\title{
BMJ Open Transition to clinical practice during the COVID-19 pandemic: a qualitative study of young doctors' experiences in Brazil and Ireland
}

Erik Montagna, ${ }^{1}$ Jessica Donohoe, ${ }^{2}$ Victor Zaia, ${ }^{1}$ Eileen Duggan, ${ }^{2}$ Paula O'Leary, ${ }^{2}$ John Waddington, ${ }^{3,4}$ Colm O'Tuathaigh (1) ${ }^{2}$

To cite: Montagna $\mathrm{E}$, Donohoe J, Zaia V, et al. Transition to clinical practice during the COVID-19 pandemic: a qualitative study of young doctors' experiences in Brazil and Ireland. BMJ Open 2021;11:e053423. doi:10.1136/ bmjopen-2021-053423

- Prepublication history and additional supplemental material for this paper are available online. To view these files, please visit the journal online (http://dx.doi.org/10.1136/ bmjopen-2021-053423).

Received 13 May 2021 Accepted 06 September 2021

Check for updates

(c) Author(s) (or their employer(s)) 2021. Re-use permitted under CC BY-NC. No commercial re-use. See rights and permissions. Published by BMJ.

${ }^{1}$ Faculdade de Medicina do ABC (FMABC), Centro Universitário Saúde ABC, São Paulo, Brazil

${ }^{2}$ School of Medicine, University College Cork, Cork, Ireland

${ }^{3}$ School of Pharmacy and

Biomolecular Sciences, Royal College of Surgeons in Ireland, Dublin, Ireland

${ }^{4}$ Jiangsu Key Laboratory of Neuropsychiatric Diseases and College of Pharmaceutical Sciences, Soochow University, Suzhou, Jiangsu, China

Correspondence to

Dr Colm 0'Tuathaigh;

c.otuathaigh@ucc.ie

\section{ABSTRACT}

Objectives To explore and compare the perspectives of junior doctors in Brazil and Ireland regarding transition and professional socialisation during the COVID-19 pandemic, with the purpose of identifying better ways to support doctors as they assume their new professional role. Design 27 semistructured interviews. Transcripts were analysed using qualitative thematic analysis. Cruess' framework of professional socialisation in medicine supported the interpretation of these data

Setting Public health hospitals across four Brazilian states (Santa Catarina, São Paulo, Ceará, Paraíba) and County Cork in the South of Ireland.

Participants Twenty-seven male and female medical junior doctors who had graduated between November 2019 and April 2020.

Results Fourteen Brazilian and 13 Irish junior doctors were interviewed for this study. Entry to clinical practice during the pandemic had a significant impact on factors influencing the professional socialisation of junior doctors. This impact was reflected across the following six thematic areas: lack of preparedness; disrupted trajectory of role adaptation; fewer opportunities for experiential learning; solidarity and isolation; altered interactions with patients; challenges to health and well-being.

Conclusions Transition to clinical practice is an important stage in junior doctors' professional socialisation and identity formation. The COVID-19 pandemic created the opportunity for medical graduates to enter the workforce earlier than usual. Entering the workforce during this period created a lack of confidence among junior doctors concerning the boundaries of their new role and responsibilities, while simultaneously disrupting their social integration. Priorities to mitigate the impact of COVID-19 and future pandemics on this transition are presented.

\section{INTRODUCTION}

COVID-19 was declared a pandemic by the WHO on 11 March 2020. It quickly escalated into a global health crisis, prompting an unprecedented emergency public health response from governments worldwide. Such changes have also impacted on delivery of healthcare, including a shift to telehealth

\section{STRENGTHS AND LIMITATIONS OF THIS STUDY}

$\Rightarrow$ This is the first study to employ a detailed and comprehensive qualitative approach to compare the impact of the COVID-19 pandemic on factors influencing the professional socialisation of junior doctors entering clinical practice across two international locations.

$\Rightarrow$ Use of a retrospective design precludes any conclusions about the long-term effects of the pandemic on these doctors' professional identity formation.

$\Rightarrow$ The study design does not allow us to fully disambiguate transitional challenges unrelated to the current pandemic which are experienced by junior doctors, relative to concerns which might be exacerbated by COVID-19.

for primary care, deferral of scheduled elective procedures and restructuring of clinical teams. ${ }^{1}$

The first cases of COVID-19 in the state of São Paulo (SP) in Brazil and Ireland were confirmed on 26 and 29 February 2020, respectively. In both locations, the number of confirmed cases grew in a classical exponential curve, with a rapid rate per day $(\sim 25 \%)$, comparable to that observed in other countries internationally. ${ }^{2}$ Within 23 days of the first case, emergency public health decisions were taken in both locations to protect the vulnerable, minimise its impact on healthcare and reduce community transmission. ${ }^{34}$

Medical education has also been severely impacted by COVID-19, requiring substantive immediate and longer term adjustments. In line with other university courses, the pandemic gave rise to the closure of medical school campuses and a rapid switch to onlinebased teaching and assessment. ${ }^{15}$ In both Brazil and Ireland students had clinical placements interrupted or cancelled, with many of these activities adapted to virtual learning environments. $^{6-8}$ The scale of the public 
health crisis prompted many medical schools to bring forward graduation, to allow graduates to enter the workforce months earlier than usual. ${ }^{9-11}$ Continued provision of medical education in the ongoing pandemic environment has necessitated radical restructuring of curricula and assessment. ${ }^{912}$

The transition from medical school to clinical practice is a time of uncertainty for the new doctors. How they experience the transition can affect their developing professional identity ${ }^{13-15}$ and these issues can persist beyond the immediate transition period. ${ }^{16}{ }^{17}$ Assuming the role of junior doctor requires a shift in perspective from the predominant position of observer to that of active participant, adapting to workplace demands and taking on independent responsibility for patient care. ${ }^{18} \mathrm{~A}$ recent study of newly graduated Irish doctors revealed a complex picture of the hopes and fears of medical students at the threshold of clinical practice. ${ }^{19}$ The experience of anticipation of transition was characterised by expectation of an abrupt transition, mixed feelings regarding commencing practice and a key role for the hidden curriculum in shaping participants' understanding of what was expected of them. ${ }^{19}$ This account is consistent with the theoretical framework proposed by Cruess and colleagues, ${ }^{20}{ }^{21}$ where the transition journey from medical student to doctor is described as one of professional socialisation. This process involves adaptive integration of work-based norms, values, knowledge and expected roles. Therein, significant factors influencing professional socialisation include role models, clinical experience, features of the clinical learning environment, attitudes of colleagues and peers and interactions with patients. $^{20}$

Despite ongoing uncertainty regarding the remaining duration of this pandemic and its sequelae, it is recognised that measures such as social distancing and quarantine periods are likely to be in place for an extended period ${ }^{2223}$ and that these necessitate exploration and discussion of how best to manage transition to clinical practice under these conditions. ${ }^{1}$ Lack of pandemic preparedness may leave medical students vulnerable to negative physical and mental health outcomes, a particularly relevant challenge for those transitioning from student to doctor. ${ }^{9}$ Consequently, examination of the transition experience of junior doctors during public health restrictions, which can vary between countries, is necessary to devise better ways to support doctors as they assume their new professional role.

Due to broad similarity in terms of the standardised undergraduate medical curriculum in both countries, as well as the public health circumstances which lead to early entry to frontline service for both sets of medical graduates, we sought to explore and compare Brazilian and Irish doctors' expectations and experiences of entering clinical practice during the COVID-19 pandemic. Specifically, the aim of this study was to examine and compare for the first time the perceptions of junior doctors in both countries regarding the impact of COVID-19 on the transition and professional socialisation process. The results are discussed in the context of Cruess' conceptual framework of junior doctors' professional socialisation.

\section{METHODS}

\section{Study design and setting}

A descriptive qualitative design was adopted. Individual semistructured interviews with junior doctors who had graduated during either late 2019 or 2020 addressed their experiences of the transition from medical student to junior doctor. This study adopted the Consolidated Criteria for Reporting Qualitative Research. ${ }^{24}$

Participants were selected through a purposive sampling method. Junior doctor participants were recruited by EM (Santo André, Brazil) and JD (Cork, Ireland). All participants were approached to participate via email or face to face based on the personal networks of EM and JD. Former students/peers were asked to distribute the invitation to participate to eligible junior doctors with the aim of obtaining a gender-balanced sample of junior doctors. Additionally, for the Brazilian sample, researchers also sought to recruit a geographically diverse sample including representatives from different regions of Brazil. The only inclusion criterion was that all participants were required to have entered clinical practice during 2019/2020. Two of the Irish junior doctors approached were unable to contribute due to clinical commitments but none of those approached refused to participate or dropped out. Interviews were conducted until data saturation was achieved. All Brazilian and Irish participants were working in teaching hospitals and clinics at the time of the study. Brazilian interviewees comprised recently qualified doctors (2-10 months since graduation) working in the public health service of four different states (Santa Catarina, São Paulo, Ceará, Paraíba). Irish interviewees comprised a sample of new doctors $(<2$ months since graduation) working at Cork University Hospital, a public hospital that is academically affiliated with University College Cork School of Medicine.

Undergraduate medical education programmes in Brazil are typically delivered across three 2-year cycles over a 6-year period characterised by early emphasis on preclinical science training and at least 2 years of clerkship rotating across major specialties ${ }^{25}$; the last 2 years are called the cycle internship (ciclo do internato), where students focus on clinical practice through training in teaching hospitals and clinics. Newly qualified doctors are permitted to work in general practice and can apply to undertake postgraduate training (ie, residency). Residency is not mandatory and some medical doctors begin work immediately after medical school, usually in emergency or primary care settings, where many will simultaneously apply to enter residency programmes in specific specialties. In April 2020, in recognition of the pressure on health and care sectors due to COVID-19, the Education Ministry of the Brazilian government issued an ordinance authorising federal universities to fast-track 
graduation of medical students who had completed $75 \%$ of their internship credits. ${ }^{26}$

Medical education in Ireland begins with 4-6 years of undergraduate university programme. For programmes that are 5 or 6 years in length, entry is based on secondary school qualifications, while programmes that are 4 years in length require previous university degrees. The first 2 years consist almost entirely of biomedical science subjects and clinical skills teaching, followed by integration of clinical training in the affiliated teaching hospitals and primary care centres during the remaining years in a spiral approach. In contrast to Brazil, where doctors are fully registered on graduating from medical school, Irish medical school graduates receive only provisional registration and 1 year of postgraduate experience (internship) in hospital-based medicine is necessary to obtain definitive registration. During April 2020, Irish medical schools expedited graduation of medical students to allow them to start their internship posts early in May $2020{ }^{27}$

\section{Data collection}

A series of questions was developed (based on previous qualitative investigation of the transition to clinical practice $^{19}$ ) that would allow us to compare both the expectations of junior doctors prior to commencing work and their experiences following 1 month of practice. The interview guide outlined this study purpose to participants and invited them to reflect on four areas: (1) their expectations concerning transition to clinical practice and how these were influenced by entering the workforce during the COVID-19 pandemic; (2) their experiences at work during the initial month of clinical practice and how these were impacted by working in a pandemic environment; (3) the impact of working as a junior doctor during a pandemic on life outside of the hospital; (4) strategies employed to manage stress in a pandemic working environment.

JD conducted all Irish interviews and EM conducted all Brazilian interviews, each of which took place in person (and without others present) or online (using Skype, Zoom or FaceTime) in a workplace setting and ranged in duration from 20 to $40 \mathrm{~min}$. All face-to-face interviews were conducted in compliance with ongoing public health measures which were in force during the pandemic at the time of data collection, the most prominent of which were $2 \mathrm{~m}$ social distancing and mask wearing. Previous studies have suggested that in in-person study interviews are comparable in terms of quality of data collected using video calls. ${ }^{28}$ Neither interview transcripts nor thematic results were returned to participants for comment or feedback. EM is a non-clinical lecturer in medical education based in the Faculty of Medicine at Centro Universitário Saúde ABC. JD is a medical graduate and clinical researcher who commenced her medical internship during May 2020.

The interviews were audio recorded. Irish interview data were transcribed using the Otter (otter.ai) transcription app and CO'T reviewed the transcripts against the audio to ensure their accuracy. Brazilian interview data were digitally transcribed using Microsoft Word and this transcription was then reviewed by EM to verify accuracy. The Brazilian-Portuguese transcript was then translated into English using the Google Translate (translate. google.com) service. EM and VZ are Portuguese-English speakers, and they checked the translation accuracy and performed a back translation of the interviews. Finally, each English translation was then jointly reviewed and finalised by CO'T and EM, addressing both grammatical errors and issues related to idioms and expressions. Each transcript was allocated a unique identifier (Cork (CK) 1-13; Brazil (BR) 1-14) according to the order in which the interviews were completed.

\section{Data analysis}

Interview data were analysed using Braun and Clarke's thematic analysis approach, ${ }^{29}{ }^{30}$ a method for identifying, analysing and reporting themes within qualitative data. First, ED and CO'T completed an independent analysis of all 27 transcripts using open coding to assign inductive, content-driven labels to interview extracts. CO'T reviewed all coded transcripts and created a single, final document that reflected the complete coding scheme. Both researchers (CO'T, ED) met regularly to discuss the initial codes, identify the codes that addressed the research questions, discover relationships across the relevant codes and organise them into themes. Any discrepancies were discussed until consensus was reached. During the final stage of data analysis, meetings were held to review the analyses and to develop the final list of six themes. Throughout, researchers wrote conceptual memos about the initial codes and finalised codes being developed.

With respect to reflexivity, both ED (with a professional clinical background in midwifery) and CO'T (a non-clinical lecturer with a background in translational neuroscience) have worked for many years in medical education, with a particular focus on students in the clinical years of the undergraduate programme. This experience influenced their interpretation of interview data collected here. Additionally, both researchers have previous experience of conducting thematic analysis on semistructured interview data. ${ }^{31-33}$ This experience influenced their interpretation of interview data collected here.

\section{The theoretical lens}

The theoretical framework of professional identity formation (PIF) in medical doctors proposed by Cruess and colleagues ${ }^{20}{ }^{21}$ describes the transformation from medical student to doctor as one of professional socialisation, where professional identity is a representation of the integration of work-based norms, values, beliefs, knowledge and expected roles. Here, identity formation is affected by several factors including role models, clinical experience, clinical learning environment features, attitudes of colleagues and peers and interactions with 


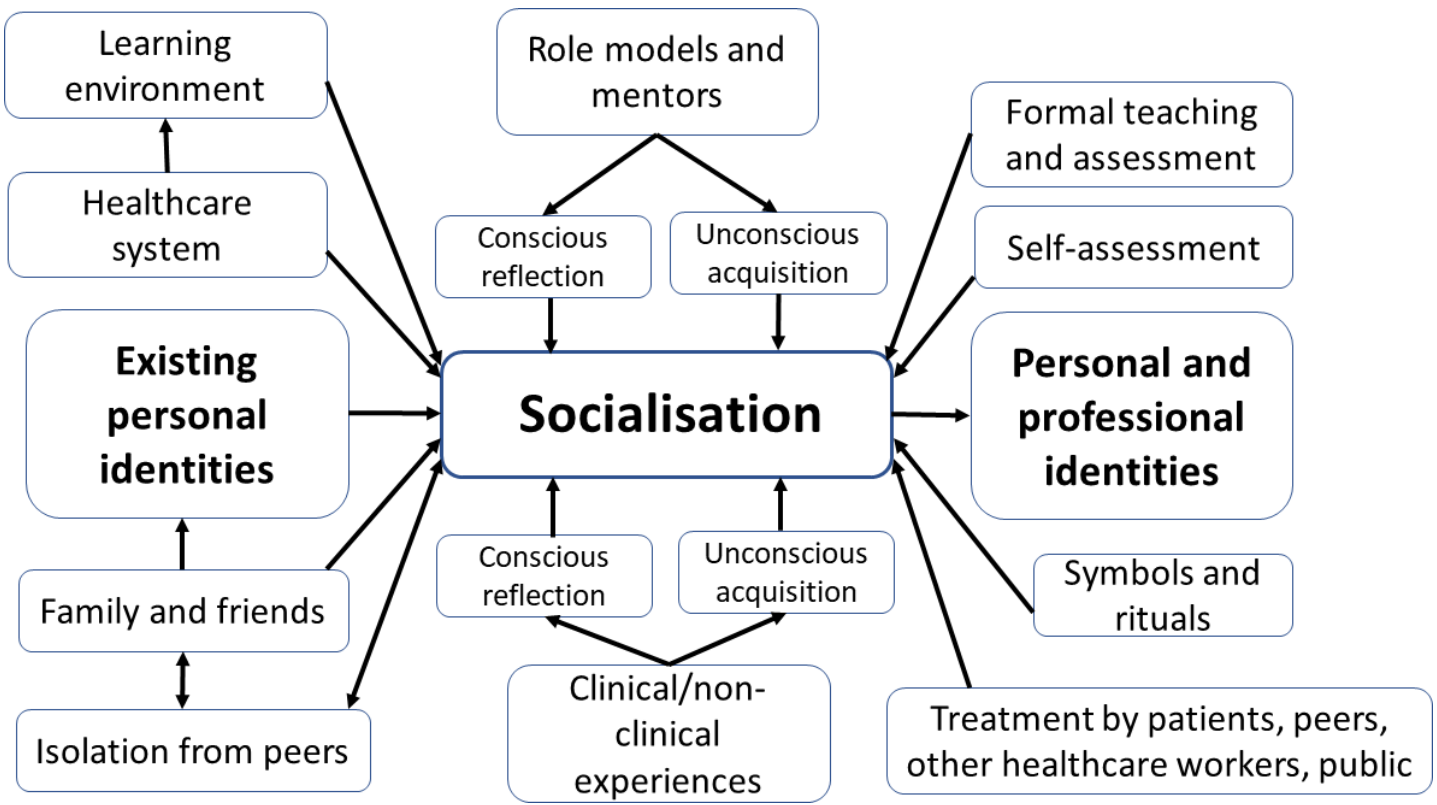

Figure 1 Schematic representation of factors influencing the process of junior doctors' professional socialisation in identity formation, as described in Cruess' conceptual framework. ${ }^{20}$

patients (figure 1). These factors interact with existing traits and support networks to influence the development of a professional identity. ${ }^{34}$ This framework ${ }^{20}$ was used to inform the interpretation and discussion of study findings. It did not inform the design or development of the interview guide; rather, we conducted a primarylevel thematic analysis to determine and identify themes, and we used Cruess' framework as a conceptual lens for a theory-driven interpretation of the study findings.

\section{Patient and public involvement}

It was not appropriate or possible to involve patients or the public in the design of this research.

\section{RESULTS}

Fourteen Brazilian and 13 Irish junior doctors were recruited and interviewed. In the Brazilian sample, most of the participants were female $(8 / 14)$, with an average of 27.4 years (range: $24-35)$, and the majority (9/14) commenced their postgraduate training during February 2020. In the Irish sample, most of the participants were male $(7 / 13)$, with an average age of 24.9 years (range: 23-32), and all commenced their hospital internship posts during May 2020. Demographic and educational details for participants are available in online supplemental table 1 .

Six overarching themes emerged from the analysis: lack of preparedness; disrupted trajectory of role adaptation; impact on opportunities for experiential learning; solidarity and isolation; altered interactions with patients; challenges to health and well-being. Direct quotes are used to support the interpretations as evidence that they are grounded in the data. Illustrative quotations are provided in tables 1-6 for each of the themes.

\section{Lack of preparedness}

When asked to outline expectations regarding the first 2 months as a qualified and practising junior doctor, interviewees reported a strong perception of lack of preparedness (see table 1 for illustrative comments; C1). Unrelated to the public health situation, their concerns were based on a lack of confidence around managing clinical uncertainty, absence of familiarity with hospital systems (eg, information technology (IT), ordering investigations, etc), as well as a sharp appreciation of the challenge of translation of theoretical knowledge into practice as a responsible physician (C2, C3). These anxieties were heightened by their expectations concerning starting work during the COVID-19 pandemic, where they reported additional trepidation related to early and abrupt entry to the workforce, lack of preparedness of health systems for the pandemic and a general sense of being 'thrown in at the deep end' $(\mathrm{C} 4, \mathrm{C} 5)$. When asked to reflect on their first month in the role of junior doctor, lack of preparedness was again cited as a significant factor; this was centred on increased responsibility for patient care and included day-to-day challenges related to case, task and time management, as well as working within hospital systems. Among Brazilian interviewees, these challenges were worsened by the reorganisation of hospital services in response to COVID-19, leading to a reduction in time available with, and clinical supervision from, senior colleagues (C6). Among Irish interviewees, these challenges were ameliorated by the presence and support provided by senior interns (C7, C8). All respondents confirmed that the undergraduate curriculum could not have better prepared them for their roles as junior doctors working during COVID-19, given its unprecedented nature. However, they recommended 
Table 1 Illustrative comments for the theme 'Lack of preparedness'

\begin{tabular}{|c|c|c|}
\hline Interviewee & Comment (C) & Extract \\
\hline BR10 & 1 & $\begin{array}{l}\text { I felt that we left the college theoretically very well, but that sometimes the practical part was } \\
\text { impaired a little. I think that was it. }\end{array}$ \\
\hline BR2 & 4 & $\begin{array}{l}\text { When it started (the pandemic) I was cautious with my choices as a doctor, because I didn't } \\
\text { have complete practical experience... }\end{array}$ \\
\hline CK7 & 5 & $\begin{array}{l}\text { We knew we were starting early. They did give us a lot of time. I suppose it was a bit of a } \\
\text { shock. You know, that we're starting a bit earlier. And obviously, we didn't finish college. I } \\
\text { suppose I was still as nervous if not more nervous. }\end{array}$ \\
\hline CK3 & 7 & $\begin{array}{l}\text { I think it's hard to like gauge what you're supposed to be doing. People are telling you to } \\
\text { do things that you're not comfortable with, you know, is this where I should be? And then } \\
\text { realising no, actually, that's out of my comfort zone. I shouldn't be doing that... but I think I } \\
\text { actually think there were less issues these days than there would have been before because I } \\
\text { had the other (senior) interns to show us what to do. }\end{array}$ \\
\hline CK3 & 8 & $\begin{array}{l}\text { It was mixed emotions because on the one hand, I felt that we were being thrown in the deep } \\
\text { end... but at the same time, I think I felt a little bit more comfortable in the fact that we were } \\
\text { starting early, because there are other interns there to help us and to kind of give us some } \\
\text { guidance. }\end{array}$ \\
\hline
\end{tabular}

BR, Brazil; CK, Cork.

that early patient exposure and a greater focus on the practicalities of the professional duties of a junior doctor would lessen the impact of the perceived abruptness of the transition.

\section{Disrupted trajectory of role adaptation}

Junior doctors expressed anxiety and a lack of confidence concerning the expectations and boundaries of their new professional role and the added independent responsibility of care (in domains of clinical decision-making, avoidance of medical error), and they expected a trajectory of adaptation to new role and responsibilities (see table 2 for illustrative comments; C1-C6). Both sets of interviewees acknowledged the expectation that confidence would increase with experience and support from senior colleagues, but also expressed concern that this trajectory would be disrupted by reduced clinical opportunities and supervision due to COVID-19 (C7-C9). At the end of the first month in their current position, they reported a partial sense of adaptation to the demands of their new role, with anxiety giving way to reassurance based on both increased knowledge and experience, as well as use of evidence-based medicine skills to manage unfamiliar clinical scenarios (C10, C11). Negative influences on this process of adaptation were confirmed to include less clinical exposure during the pandemic, due to cancellation of elective procedures and outpatient surgeries, as well as absence of information related to management of patients with COVID-19 (C12). Their concerns extended to training opportunities available during the months ahead. Among both groups, there were concerns that limited clinical exposure and COVID-19-related disruption to medical research (including conduct of research and presentation opportunities; C13) would reduce the competitiveness of their applications to residency or postgraduate training posts. Additionally, they noted that early entry of graduates into the health workplace during 2020 , as well as the increase in the number of returning overseas medical graduates, would translate into increased competition for future specialty training positions (C14).

\section{Impact on experiential learning opportunities}

Unrelated to the public health situation, interviewees expected an overwhelming workload, long hours and the challenge of managing complex clinical situations (see table 3 for illustrative comments; C1-C3); these concerns were heightened by entering the workforce during COVID-19. They expected 'wartime 
Table 2 Illustrative comments for the theme 'Disrupted trajectory of role adaptation'

\begin{tabular}{|c|c|c|}
\hline Interviewee & Comment (C) & Extract \\
\hline BR9 & 1 & $\begin{array}{l}\text { Nervous because we were taking care of people's lives. So we were going to try to treat as best } \\
\text { as possible, and we were afraid to do something, because I don't know ... to do something } \\
\text { that didn't work out. }\end{array}$ \\
\hline CK6 & 2 & $\begin{array}{l}\text { I thought I was going to have a lot of responsibility, but it was still a shock when I went in, and } \\
\text { people were asking me questions. }\end{array}$ \\
\hline BR8 & 3 & $\begin{array}{l}\text { That nervousness of responsibility. But, as everything was adjusting, I ended up liking it a lot, } \\
\text { right? }\end{array}$ \\
\hline CK8 & 4 & $\begin{array}{l}\text { I suppose not knowing what would be expected of you and like the limits to your job....and so I } \\
\text { think, trying to know what your boundaries are and what you should and shouldn't be expected } \\
\text { to do to, like, make sure you're not being taken advantage of kind of thing really. }\end{array}$ \\
\hline CK2 & 5 & $\begin{array}{l}\text { I found it difficult to get used throughout to what was expected of me. I almost wish I had a job } \\
\text { description. }\end{array}$ \\
\hline CK10 & 8 & $\begin{array}{l}\text { I seem to be learning a lot on the go, and there's a certain degree of stress associated with } \\
\text { not being experienced and being the kind of lowest rung in the ladder but then that that would } \\
\text { dissipate over a few months and you probably improve very quickly, hopefully. }\end{array}$ \\
\hline CK4 & 9 & $\begin{array}{l}\text { Maybe that there would be less interaction with the other people in the team, that there might } \\
\text { not be enough (other doctors), like if there was a surge there wouldn't be enough as many } \\
\text { people working together, you might be a bit more on your own because there'll be like staffing } \\
\text { issues. }\end{array}$ \\
\hline BR9 & 10 & $\begin{array}{l}\text { Everything for me was new...so, at this point in the last month, I felt much more confident, } \\
\text { taking action, discussing cases.... in five months of residency it has really changed. }\end{array}$ \\
\hline CK4 & 14 & $\begin{array}{l}\text { There are so many interns and so many people that didn't get to emigrate that I just think that } \\
\text { maybe next year, there might be a problem...I've heard about some interns this year that are } \\
\text { finding it difficult to get training posts. }\end{array}$ \\
\hline
\end{tabular}

BR, Brazil; CK, Cork.

conditions', including long shifts and increased stress related to management of serious COVID-19-related emergencies, yet simultaneously fewer opportunities for gaining clinical experience in preferred areas $(\mathrm{C} 4, \mathrm{C} 5)$. In particular, the experiences of Brazilian interviewees during the first month reflected these concerns, especially as they relate to COVID-19 adding to case complexity; this added challenge was enhanced by the lack of information around the management of this new diagnosis and the requirement for training in relevant procedural skills (C6, C7). In contrast, Irish junior doctors highlighted that fewer patients without COVID-19 in hospital during this period meant more time for clinical teaching and closer supervision from senior colleagues (C8, C9). Both groups noted that while their undergraduate curriculum provided strong grounding for a generalist, further training in management of complex emergency cases (potentially using simulation methods) and increased training in COVID-19-relevant procedural skills (eg, intubation) would be beneficial.

\section{Solidarity and isolation}

Young doctors' professional socialisation is guided by experiential learning opportunities and by interactions with other doctors and health professionals. Here, junior doctors expected that increased independence and responsibilities would be accompanied 
Table 3 Illustrative comments for the theme 'Impact on experiential learning opportunities'

\begin{tabular}{|c|c|c|}
\hline Interviewee & Comment (C) & Extract \\
\hline BR5 & 1 & $\begin{array}{l}\text { I always had an idea that it would be quite 'busy'. I thought that I would be constantly going } \\
\text { from one shift to another. }\end{array}$ \\
\hline BR3 & 4 & $\begin{array}{l}\text { We were thrown into a kind of war scenario, right? I had my graduation brought forward } \\
\text { by almost two months, because I graduate in May, and we were forecasted to graduate in } \\
\text { July....However, really, we were thrown into a very unfavorable scenario in terms of working } \\
\text { conditions, right? Because they are hospitals, often field hospitals, with patients in a state of } \\
\text { health that is often very serious. }\end{array}$ \\
\hline BR11 & 6 & $\begin{array}{l}\text { I think what really impressed me was really the realisation of a challenge that I feared, which } \\
\text { was that of dealing with patients very different from what I was used to as an undergraduate } \\
\text { student...look, I believe that the pandemic has resulted in patients with even more severe } \\
\text { conditions. Despite my residency being in a surgical area, we see many patients with } \\
\text { Covid-19 that arrived with conditions that needed surgery such as intestinal obstruction, } \\
\text { arterial occlusion and these patients progressed very badly after the surgery because of the } \\
\text { viral infection. }\end{array}$ \\
\hline BR13 & 7 & $\begin{array}{l}\text { But, in relation to Covid-19, I certainly learned a lot in treatment, in decision making, in new } \\
\text { therapies that at the beginning of the residency I thought I would not be able to achieve. }\end{array}$ \\
\hline
\end{tabular}

BR, Brazil; CK, Cork.

by support from colleagues when required, especially in relation to managing uncertainty in clinical situations (see table 4 for illustrative comments; C1). At the same time, they noted that one of the biggest challenges expected of their role would involve working as part of a clinical team and securing the support of senior colleagues (C2). Irish interviewees expected that early entry to the workforce during COVID-19 would be accompanied by extra support from senior colleagues and doctors in internship from the previous year's graduating class who were still in post (C3). Brazilian and (to a lesser extent) Irish doctors noted great camaraderie among medical colleagues, as well as more knowledge sharing across specialties and additional collaboration during a period of 'shared adversity' in that first month of practice (C4-C6). They experienced significant interprofessional collaboration and a greater appreciation of the distinct contribution of other hospital-based health professionals. At the same time, both hospital and wider infection control measures, as well as fears regarding contracting COVID-19, meant fewer opportunities for socialisation among trainee peers and for the integration and teamwork that can lead to professional trust $(\mathrm{C} 8, \mathrm{C} 9)$. Irish doctors also noted the hindrance effect of personal protective equipment (PPE) on interprofessional communication.

Outside of the working environment, both groups noted the isolating effects of working in a hospital with patients with COVID-19, where the obligation to reduce social contact and associated social distancing requirements may reduce social support (including the opportunity to share concerns with peers) during a particularly stressful time (C10).

\section{Altered interactions with patients}

In advance of starting work in hospitals, both groups noted that one of the challenges of working with patients during the COVID-19 pandemic would include both interacting with patients in an infection 
Table 4 Illustrative comments for the theme 'Solidarity and isolation'

\begin{tabular}{|c|c|c|}
\hline Interviewee & $\begin{array}{l}\text { Comment } \\
\text { (C) }\end{array}$ & Extract \\
\hline CK5 & 1 & $\begin{array}{l}\text { I kind of watched people in placement and stuff and thought, oh my God, that's, like, way more } \\
\text { than I've ever done. A lot of responsibility is definitely scary...and I did kind of get the feeling } \\
\text { that you're well supported in the hospitals, just from talking to other interns. }\end{array}$ \\
\hline BR3 & 2 & $\begin{array}{l}\text { I imagined finding an environment much more, how can I say, aggressive when it comes to } \\
\text { competition between colleagues. From what I heard in reports from some colleagues, a more } \\
\text { competitive environment, right? And it is quite different from what I expected. }\end{array}$ \\
\hline CK8 & 3 & $\begin{array}{l}\text { There's a bit of anxiety coming in, in terms of like Covid-19 being everywhere and you know, } \\
\text { coming into work in a hospital, the plus side was that we did get all the extra time with the old } \\
\text { interns...(we were not) under the stress that you'd normally be under if you're just thrown in the } \\
\text { deep end on your own. }\end{array}$ \\
\hline BR3 & 4 & $\begin{array}{l}\text { I imagined finding a much more competitive scenario, much less united. Perhaps the crisis had } \\
\text { an impact on this aspect, bringing a feeling of greater unity between health professionals. }\end{array}$ \\
\hline BR10 & 5 & $\begin{array}{l}\text { I think that at the time of Covid-19, this relationship became even stronger. I thought that the } \\
\text { health professionals got together a lot. I realized that people who previously did not value the } \\
\text { services of the nurse, the nursing technician, started to give credit... we take turns to have lunch } \\
\text { to avoid crowding, so there was this social distance. But I think the teamwork was better. }\end{array}$ \\
\hline CK11 & 6 & $\begin{array}{l}\text { l've had no issue, everyone's quite pleasant and nice and (they have) an understanding of our } \\
\text { situation, that we're coming in during a time when everyone is quite under stress. }\end{array}$ \\
\hline BR4 & 7 & $\begin{array}{l}\text { We are in the first year, right ?! We hear that people get to know each other, that they have more } \\
\text { contact. I don't know many of my fellow first-year residents. }\end{array}$ \\
\hline CK6 & 8 & $\begin{array}{l}\text { I think maybe there would be more of a social aspect in the hospital if there's wasn't this } \\
\text { (Covid-19), and maybe you'd have a better relationship with your team members. }\end{array}$ \\
\hline CK2 & 9 & $\begin{array}{l}\text { I do find that the masks definitely (impair communication), maybe with the doctors because you } \\
\text { spend more time with them it's grand but like the nurses on the ward sometimes like because } \\
\text { you can't be as warm with them, it can almost be like when you're asking them for something } \\
\text { that you're telling them to do something. }\end{array}$ \\
\hline CK3 & 10 & $\begin{array}{l}\text { So I couldn't see my friends as much as I would have liked to, couldn't talk to my friends as } \\
\text { much as I would have liked to.... need to just figure it out on my own. }\end{array}$ \\
\hline
\end{tabular}

BR, Brazil; CK, Cork.

control environment and attempting to give evidencebased information regarding transmission risk and management of COVID-19 to patients in the absence of definitive evidence (see table 5 for illustrative comments; C1, C2). Following 1 month in post, junior doctors highlighted the disruptive impact of PPE and other infection control measures on doctor-patient communication, as well as other important aspects of clinical interactions (C3). They noted significant patient distrust and anxiety towards the hospital environment (manifesting as avoidance of hospital appointments and investigations) due to fear of contracting COVID-19 from other patients or healthcare workers (C4, C5). On the other hand, both sets of interviewees reported hastier functional examinations and less physical examination to reduce patient time in the clinical area (C6). They also reported greater difficulty in establishing rapport and building empathy with patients and highlighted the need for doctors to focus their efforts on empathic communication in order to allay patients' anxieties and fears, build trust and foster relationships (C7, C8). PPE, especially masks, were reported to have a particularly negative impact on communication with elderly and hard-of-hearing patients (C9).

\section{Challenges to health and well-being}

Both groups reported feelings of generalised anxiety, stress and insecurity in advance of commencing their first post (see table 6 for illustrative comments; C1, C2). These concerns were in part focused on the personal health risks of working in a clinical environment during the COVID-19 pandemic and the same comments were recorded following 1 month of practice (C3). Approximately half of interviewees expressed fears about contracting COVID-19 and three volunteered that they had indeed contracted the disease. Those who reported no fears of contracting the virus or who reported a reduction in their concerns over time emphasised either that they were taking all precautions or that their concerns were assuaged due to nascent understanding of risk stratification for severe COVID-19 illness (C4, C5). Brazilian doctors felt adequately protected by available PPE, despite initial access limitations and the variable quantity and quality of PPE during the early stages of the pandemic (BR12). While Irish interns confirmed that 
Table 5 Illustrative comments for the theme 'Altered interactions with patients'

\begin{tabular}{|c|c|c|}
\hline Interviewee & Comment (C) & Extract \\
\hline CK11 & 1 & $\begin{array}{l}\text { I hadn't anticipated a challenge. That is, I wasn't quite sure how interactions with patients } \\
\text { would go. No, because I suppose when we weren't in the hospital, we were sitting at home } \\
\text { waiting to start, we didn't know what the story was with people wearing masks and what you } \\
\text { do when you interact with a patient. }\end{array}$ \\
\hline BR13 & 2 & $\begin{array}{l}\text { Because even today we don't know what really makes Covid-19 better, and many people talk } \\
\text { about some medications that theoretically would improve it. But we continue research and } \\
\text { see that they don't. In fact, they worsen the condition. That was a very big challenge. In this } \\
\text { case, you also have to guide the population that what they are asking for is sometimes not the } \\
\text { best for them. }\end{array}$ \\
\hline BR9 & 3 & $\begin{array}{l}\text { It has totally changed, totally changed. We get there and don't even know who the person } \\
\text { with the mask is, just see the eyes, have no idea, have no gestures, we can't see if it's } \\
\text { pleasing. }\end{array}$ \\
\hline CK4 & 4 & $\begin{array}{l}\text { I suppose a few patients have been wary of you coming, now it's more that l've got a few } \\
\text { questions (from patients) asking have you seen any patients with Covid-19? }\end{array}$ \\
\hline BR13 & 6 & $\begin{array}{l}\text { I think it was badly damaged (the relationship). We just say 'hi, what's going on, I'm going to } \\
\text { solve your problem, and bye', there is not much small talk, nor much time for you to discuss } \\
\text { issues with the patient and to be a little more careful. }\end{array}$ \\
\hline CK3 & 7 & $\begin{array}{l}\text { I feel like having my having the mask really affects how I deal with patients, like I feel like } \\
\text { when I'm going to see them that I have the mask on they can't see me smiling at them so that } \\
\text { they're not as comfortable as it normally would be with me. }\end{array}$ \\
\hline BR12 & 8 & $\begin{array}{l}\text { I realised that, like this, it demanded more patience, to explain it better... sometimes the } \\
\text { population is not sure about the information, they arrive with misconceptions, they arrive } \\
\text { with demands, right? Things they're seeing on TV, they then get anxious, come with several } \\
\text { demands. }\end{array}$ \\
\hline
\end{tabular}

BR, Brazil; CK, Cork.

PPE was available, they noted instances of poor adherence to infection control measures in the clinical areas and highlighted the necessity for senior clinicians to embody such measures so as to constitute appropriate role models (C7). Both groups noted that their undergraduate curriculum had prepared them for working in infection control environments (eg, gowning, aseptic and handwashing techniques).

Nearly all participants expressed concerns about transmission of infection to family or household members and several interviewees had moved away from home and/or avoided contact with friends or family to mitigate such risk (C8). Those who were not concerned lived alone and/or did not live near family members or have parents/siblings/housemates who also worked in health settings. Two doctors expressed concerns regarding housemates (also doctors) who were either interacting with teams having multidisciplinary contact or based in several different clinical settings (C9). While the majority of interviewees $(16 / 27)$ across both groups were aware of mental health supports available to junior doctors, those who indicated awareness also stated that they would not be interested in availing of such supports. One interviewee commented: 'I believe that the professionals, some professionals even feel a little ashamed to say that they follow [attend] these programs' (BR1). While recognising potential stigma associated with accessing help, interviewees paradoxically advised future graduates in the importance of self-care and support seeking (eg, '... because if you don't think about yourself, you won't be able to help other people'; BR1).

\section{DISCUSSION}

Here we demonstrate in both Brazil and Ireland that entry to clinical practice during the COVID-19 pandemic impacts adversely on several factors that are known to influence smooth transition, commencement of 
Table 6 Illustrative comments for the theme 'Challenges to health and well-being'

\begin{tabular}{|c|c|c|}
\hline Interviewee & Comment (C) & Extract \\
\hline BR3 & 1 & $\begin{array}{l}\text { On the emotional side, I already imagined it would be quite tense, right? The first jobs, the first } \\
\text { days, because it is ... there is an insecurity in relation to medical activity itself, in general, and } \\
\text { especially when it comes to a newly graduated professional. }\end{array}$ \\
\hline CK8 & 2 & $\begin{array}{l}\text { Yeah, with the old interns there, we weren't kind of like thrown in the deep end as you normally } \\
\text { would be, but I think definitely...you'd feel kind of apprehensive and I was nervous. }\end{array}$ \\
\hline CK4 & 3 & $\begin{array}{l}\text { (There are) patients with COVID-19 that like the team might be seeing. You're wary of like who's } \\
\text { going into them, which day and then who had been exposed and kind of things like that. }\end{array}$ \\
\hline CK5 & 4 & $\begin{array}{l}\text { Like at the start, I was definitely worried. But then I realised everyone was wearing masks, and } \\
\text { we're all (practicing) very good hygiene. Yeah, so the risk was actually quite low. }\end{array}$ \\
\hline BR3 & 5 & $\begin{array}{l}\text { I have to confess no. I try to guide myself like this ... based on scientific evidence, } \\
\text { understanding that medicine is based on evidence and based on statistics, on scientific } \\
\text { evidence of what we have today... the chance of me getting serious getting Covid-19 is very } \\
\text { small, very limited. }\end{array}$ \\
\hline CK12 & 7 & $\begin{array}{l}\text { When I came in first, like, everyone is in on top of each other trying to read charts and they } \\
\text { were sitting in like, ICU, anyway, I mean, yeah, there's not much social distancing going on the } \\
\text { hospital for sure. }\end{array}$ \\
\hline BR7 & 8 & $\begin{array}{l}\text { At first I ended up getting away from the family. As I don't live with my parents at home, it made } \\
\text { it easier for me. But, for sure, I reduced visits to family members and ended up walking away } \\
\text { for fear of transmitting. }\end{array}$ \\
\hline CK2 & 9 & $\begin{array}{l}\text { At the moment it's me and four other interns in our house but like the four of us work at three } \\
\text { different hospitals so that's kind of scary that maybe one of us could give it to another and then } \\
\text { bring it from one hospital into a different hospital. }\end{array}$ \\
\hline
\end{tabular}

BR, Brazil; CK, Cork; ICU, intensive care unit; PPE, personal protective equipment.

professional socialisation and PIF in young doctors. Cruess and colleagues have noted that the trajectory of professional socialisation is characterised by initially tentative and peripheral participation, followed by progressively fuller engagement via social interactions, during which the doctor's identity aligns with the community's values and norms. ${ }^{34}$

\section{Impact of COVID-19 on the transition and professional socialisation of junior doctors}

Our analysis reveals that the transition into practice during COVID-19 was perceived as more abrupt and stressful than it might otherwise have been, principally due to feelings of being "thrown in at the deep end' during a period of reorganisation of hospital services, disruption of normal patterns of clinical supervision and fewer experiential learning opportunities, as well as insecurity due to lack of information about transmission and management of COVID-19 and its effect on non-COVID-19 case complexity. Communication with both other health professionals and patients was also judged to be impaired during the COVID-19 pandemic, with quality of communication degraded due to the use of PPE and imposition of other infection control measures. Additionally, typical rapport and empathic communication with patients were replaced by feelings of mutual distrust, as well as a shift towards reduced consultation time with the patient.

Our findings elaborate previous reports by identifying many of the transitional challenges experienced by junior doctors while also identifying COVID-19related exacerbation of associated concerns. A recent qualitative examination of transition to residency in a sample of US doctors revealed a similar constellation of themes centred around individual and contextual aspects of the transition experience. ${ }^{35}$ These themes described abrupt entry into a busy and unstructured clinical environment that was characterised by ongoing challenges during their interactions with patients and healthcare team members. Feelings of lack of preparedness and a sense of being 'thrown in at the deep end' are also recurring themes in related studies. ${ }^{18} 19 \mathrm{~A}$ recent survey of final year medical students in the UK indicated that almost $60 \%$ of students were lacking in confidence and perceived preparedness going into their first intern post during the COVID-19 pandemic. $^{5}$ It has been suggested that expedited graduation and placement at the frontline may have exacerbated this transition anxiety. ${ }^{11}$ Heightened anxiety at the prospect of transitioning during COVID-19 chimes with anecdotal reports of increased stress among new doctors starting work during this pandemic. ${ }^{36}$ 
Professional socialisation involves adaptation as junior doctors move from 'legitimate peripheral participation' in medicine's community of practice to full participation ${ }^{37}$; this represents a gradual process of acquiring the identity of members of the community. ${ }^{21}$ Cruess' model posits that clinical experiences with patients and relatives are important in professional socialisation, contributing to the junior doctor's emergent clinical confidence and understanding of the values and behaviours expected in their professional role. ${ }^{38}$ The present study reports a decrease in the quantity and quality of such junior doctor-patient interactions. This finding is in line with reports of disrupted doctor-patient communication during the pandemic, where it was noted that 'the barrier of isolation has impacted patients and patient care, and has also affected the experience of the physician'. ${ }^{39}$ Here, interviewees noted that their interactions with elderly and hard-of-hearing patients were particularly affected by PPE measures and similar concerns have been documented elsewhere (eg, ref 40).

\section{Exacerbation of transition-related anxiety during the pandemic}

A sense of personal well-being and the support of family and friends are among the most important influences on a smooth transition to clinical practice and commencement of the professional socialisation process. ${ }^{2134}$ Difficulties in adapting to this early period of professional socialisation can result in anxiety, stress and feelings of burnout among young doctors. ${ }^{20}$ Importantly, young doctors are already known to exhibit elevated levels of stress ${ }^{39} 40$ and burnout ${ }^{41-43}$ as well as anxiety and/or depression ${ }^{44} 45$ during more typical circumstances. That these symptoms are most pronounced during the immediate period of transition from medical student to doctor ${ }^{46-49}$ may increase vulnerability to adversity when making that transition during the COVID-19 pandemic.

Junior doctors across both locations reported increased anxiety during this period due to fears of contracting the virus or passing it on to friends/ family. This led many to effectively isolate from their social support networks during what is already a typically stressful period in their training. In a quantitative survey of palliative care health workers, we have recently demonstrated the profound impact of COVID-19 on personal and professional well-being of patient-facing clinicians. ${ }^{50}$ Similar to that observed in the current study, among the highest rated sources of stress were fear of contracting COVID-19 or transmitting it to friends/family, and reduced social interaction with colleagues. Congruent with previous reports, ${ }^{18}$ interviewees in the present study reported a limited awareness of mental health supports and services available to junior doctors, none indicated that they had sought assistance. Previous research has also revealed a reluctance among junior doctors to admit to feeling overstressed, or to access support services, for fear of professional repercussions, for example, they would be perceived as less competent or employable. ${ }^{51}$

\section{Strategies for managing the impact of pandemic on the transition experience}

Development of strategies for minimising the impact of pandemic-related changes in the clinical environment on the transition experience must focus on areas most affected. These include preparedness for practice, doctors' health and well-being, communication with colleagues and patients and experiential learning opportunities. A review of the literature on transition interventions has noted the paucity of rigorous and outcome-focused studies looking at educational interventions targeting areas of unpreparedness. ${ }^{52}$ Choi et a $a \tilde{l}$ reported that the provision of 'student assistantship' rotations offered by selected UK medical schools, where medical students are better integrated within a clinical team so as to develop both their clinical and practical skills, played a key role in enhancing preparedness for medical student transitioning during COVID-19. Reconfiguration of such initiatives could be effective in addressing the needs of junior doctors graduating and transitioning during the COVID-19 (or indeed another) pandemic. Notably, in the present setting, Irish junior doctors stated that the acute challenge of adapting to workplace demands following early entry to practice was lessened by the overlapping presence of the previous year's medical graduates, confirming the value of nearpeer support and supervision in facilitating successful transition to practice. ${ }^{53}$ This is an area which merits further research.

Our data suggest that approaches to promoting resilience in such cohorts must incorporate individual, organisational and cultural commitment to the well-being of junior doctors. ${ }^{54}$ Resilience-promoting programmes for doctors working during this and other pandemics should specifically focus on enhancing adaptive strategies for coping and building self-efficacy. ${ }^{9}$ Interventions targeting any one of these areas can also impact in a positive sense across other related domains. For example, it has been noted that activities designed to enhance PIF can build a strong sense of shared social identity that buffers against adverse influences on mental well-being. ${ }^{34}{ }^{55}$ Another review of the efficacy of intervention for preventing burnout in junior doctors suggested that structural and organisational strategies (eg, restrictions in working hours) might also be effective for improving well-being of new doctors. ${ }^{56}$

Use of a retrospective, qualitative design precludes any conclusions about the long-term effects of transitioning during the pandemic on these doctors' PIF. Additionally, during the time frame of this study, the impact of the COVID-19 pandemic on healthcare systems was more pronounced in Brazil than in Ireland. The daily number of COVID-19-related hospitalisations and intensive care unit cases across Irish hospitals was in steady decline 
during the time when Irish doctors were commencing practice ${ }^{57}$ In contrast, the daily number of such COVID19-related cases in Brazil was rapidly rising during the corresponding period. ${ }^{58}$ Thus, although interviewees have identified commonalities across both groups with respect to their transition experiences, these were manifested on a background of differences between the study locations in relation to patterns of COVID-19 transmission and their impacts on health systems during this period. For example, as outlined in the Results section under the 'Challenges to health and well-being' theme, we note that Brazilian interviewees highlighted the impact of PPE shortages during the early stage of the pandemic crisis, whereas PPE availability was not cited as an issue by our Irish interviewees. This is because PPE availability for Irish healthcare staff was perceived to be sufficient at the time of data collection (October 2020) compared with earlier in the pandemic (March to April 2020). ${ }^{59}$ The cross-sectional design of the study precluded a more nuanced examination of the challenges faced by junior doctors which would likely fluctuate across the phases of the COVID-19 pandemic.

\section{Limitations}

One of the limitations of the study is that it may be assumed that the specific work context would have influenced the young doctors' experience during the pandemic, but this factor was not explored in the current analysis. The current sample was based (and in some case rotated through several) across diverse range of hospital-based clinical settings, and previous studies have shown that those with greater direct exposure to patients with COVID-19 in terms of proximity and time reported greater levels of stress and anxiety during the first 6 months of the pandemic. ${ }^{50}$ Additionally, the study design does not allow the distinction to be made between transitional challenges unrelated to the current pandemic which are experienced by new medical graduates, relative to concerns which might be exacerbated by COVID-19. This would highlight the need for longitudinal studies which may inform on the PIF of these junior doctors, and the long-term psychological sequelae and supports required. Lastly, despite the identification of common themes across both groups, sociocultural differences across both locations might have contributed to the results in a manner not measurable using the present design.

\section{CONCLUSIONS}

In summary, optimising the preparation and graduation of qualified doctors is needed now more than any time in living memory. The impact of COVID-19 on undergraduate medical education and preparation for clinical practice is likely to be long lasting and significant. We have demonstrated in an international sample of young doctors that entering clinical practice during the COVID-19 pandemic affected several factors that influence the process of professional socialisation. The insights arising from this study are expected to inform undergraduate and postgraduate curricular design and the implementation of appropriate interventions to support transition during the current pandemic.

Contributors CO'T and EM developed the premise of the work. CO'T, ED, JD and VZ developed the interview guide, recruited participants and collected the data. CO'T, ED, EM, JW and VZ completed the data analysis. CO'T, EM, JW and PO'L wrote the first draft of the article. All authors edited and commented on multiple drafts of this article and approved the final version of the manuscript.

Funding The authors have not declared a specific grant for this research from any funding agency in the public, commercial or not-for-profit sectors.

Competing interests None declared.

Patient consent for publication Not required.

Ethics approval The Institutional Research Ethics Committee of Centro Universitário Saúde ABC (CAAE: 40227120.1.0000.0082) and the Social Research Ethics Committee of University College Cork (07/20) gave approval for this study.

Provenance and peer review Not commissioned; externally peer reviewed.

Data availability statement Data are available upon reasonable request. All data relevant to the study are included in the article or uploaded as supplementary information. Data are available upon reasonable request. Alldata relevant to the study are included in the article or uploaded as supplemental information. The data including relevant quotations are contained withinthe manuscript file. Raw data are stored on anencrypted, secure University network and can be reproduced upon request.

Supplemental material This content has been supplied by the author(s). It has not been vetted by BMJ Publishing Group Limited (BMJ) and may not have been peer-reviewed. Any opinions or recommendations discussed are solely those of the author(s) and are not endorsed by BMJ. BMJ disclaims all liability and responsibility arising from any reliance placed on the content. Where the content includes any translated material, BMJ does not warrant the accuracy and reliability of the translations (including but not limited to local regulations, clinical guidelines, terminology, drug names and drug dosages), and is not responsible for any error and/or omissions arising from translation and adaptation or otherwise.

Open access This is an open access article distributed in accordance with the Creative Commons Attribution Non Commercial (CC BY-NC 4.0) license, which permits others to distribute, remix, adapt, build upon this work non-commercially, and license their derivative works on different terms, provided the original work is properly cited, appropriate credit is given, any changes made indicated, and the use is non-commercial. See: http://creativecommons.org/licenses/by-nc/4.0/.

ORCID iD

Colm 0'Tuathaigh http://orcid.org/0000-0003-1365-1606

\section{REFERENCES}

1 Rose S. Medical student education in the time of COVID-19. JAMA 2020;323:2131-2.

2 World Health Organisation, 2020. Available: https://www.who.int/ emergencies/diseases/novel-coronavirus-2019 [Accessed 05 Oct 2020].

3 Garcia PJ, Alarcón A, Bayer A. COVID-19 response in Latin America. Am J Trop Med Hygiene 2020;103:1765-72.

4 Serdan TDA, Masi LN, Gorjao R, et al. COVID-19 in Brazil: historical cases, disease milestones, and estimated outbreak peak. Travel Med Infect Dis 2020;38:101733.

5 Choi B, Jegatheeswaran L, Minocha A, et al. The impact of the COVID-19 pandemic on final year medical students in the United Kingdom: a national survey. BMC Med Educ 2020;20:206.

6 Carrascosa MMC, Campos Tde, Sampaio JE, et al. Medical interns and COVID-19: results of national research. Rev Assoc Med Bras 2020;66:812-7.

7 Chinelatto LA, Costa TRD, Medeiros VMB. What you gain and what you lose in COVID-19: perception of medical students on their education. Clinics 2020;75:e2133.

8 Rasmussen S, Sperling P, Poulsen MS, et al. Medical students for health-care staff shortages during the COVID-19 pandemic. Lancet 2020;395:e79-80. 
9 O'Byrne L, Gavin B, McNicholas F. Medical students and COVID-19: the need for pandemic preparedness. J Med Ethics 2020;46:623-6.

10 Redford G. "Itching to get back in": Medical students graduate early to join the fight, 2020. Available: https://www.aamc.org/newsinsights/itching-get-back-medical-students-graduate-early-join-fight [Accessed 05 Oct 2020].

11 Siddique $\mathrm{H}$. Final-Year medical students graduate early to fight Covid-19, 2020. Available: https://www.theguardian.com/world/ 2020/mar/20/final-year-medical-students-graduate-early-fightcoronavirus-covid-19 [Accessed 05 Oct 2020].

12 Rolak S, Keefe AM, Davidson EL, et al. Impacts and challenges of United States medical students during the COVID-19 pandemic. World J Clin Cases 2020;8:3136-41.

13 Ackerman A, Graham M, Schmidt H, et al. Critical events in the lives of interns. J Gen Intern Med 2009;24:27-32.

14 Westerman M, Teunissen PW, van der Vleuten CPM, et al. Understanding the transition from resident to attending physician: a transdisciplinary, qualitative study. Acad Med 2010;85:1914-9.

15 Haruta J, Ozone S, Hamano J. Doctors' professional identity and socialisation from medical students to staff doctors in Japan: narrative analysis in qualitative research from a family physician perspective. BMJ Open 2020;10:e035300.

16 Brennan N, Corrigan O, Allard J, et al. The transition from medical student to junior doctor: today's experiences of tomorrow's doctors. Med Educ 2010;44:449-58

17 Atherley A, Dolmans D, Hu W, et al. Beyond the struggles: a scoping review on the transition to undergraduate clinical training. Med Educ 2019;53:559-70.

18 Sturman N, Tan Z, Turner J. "A steep learning curve": junior doctor perspectives on the transition from medical student to the healthcare workplace. BMC Med Educ 2017;17:92.

19 Coakley N, O'Leary P, Bennett D. 'Waiting in the wings'; lived experience at the threshold of clinical practice. Med Educ 2019;53:698-709.

20 Cruess RL, Cruess SR, Boudreau JD, et al. A schematic representation of the professional identity formation and socialization of medical students and residents: a guide for medical educators. Acad Med 2015;90:718-25.

21 Cruess RL, Cruess SR, Steinert Y. Medicine as a community of practice: implications for medical education. Acad Med 2018;93:185-91.

22 Kissler SM, Tedijanto C, Goldstein E, et al. Projecting the transmission dynamics of SARS-CoV-2 through the postpandemic period. Science 2020;368:860-8.

23 Murray CJL, Piot P. The potential future of the COVID-19 pandemic: will SARS-CoV-2 become a recurrent seasonal infection? JAMA 2021;325:1249-50.

24 Tong A, Sainsbury P, Craig J. Consolidated criteria for reporting qualitative research (COREQ): a 32-item checklist for interviews and focus groups. Int J Qual Health Care 2007;19:349-57.

25 Antunes dos Santos R, Nunes MdoPT. Medical education in Brazil. Med Teach 2019;41:1106-11.

26 PORTARIA N 374, DE 3 DE ABRIL DE 2020, 2020. Available: https:// www.in.gov.br/en/web/dou/-/portaria-n-374-de-3-de-abril-de-2020251289249 [Accessed 05 Oct 2020].

27 Roche B. Taoiseach pledges that 1,000 medicine graduates will be offered an internship, 2020. Available: https://www.irishtimes.com/ news/ireland/irish-news/taoiseach-pledges-that-1-000-medicinegraduates-will-be-offered-an-internship-1.4231678 [Accessed 05 Oct 2020].

28 Krouwel M, Jolly K, Greenfield S. Comparing Skype (video calling) and in-person qualitative interview modes in a study of people with irritable bowel syndrome - an exploratory comparative analysis. $B M C$ Med Res Methodol 2019;19:219.

29 Braun V, Clarke V. Using thematic analysis in psychology. Qual Res Psychol 2006;3:77-101.

30 Braun V, Clarke V. Reflecting on reflexive thematic analysis. Qual Res Sport Exerc Health 2019;11:589-97.

31 O'Tuathaigh CMP, Duggan E, Khashan AS, et al. Selection of student-selected component [SSCs] modules across the medical undergraduate curriculum: relationship with motivational factors. Med Teach 2012;34:813-20.

32 Cudmore V, Henn P, O'Tuathaigh CMP, et al. Age-Related hearing loss and communication breakdown in the clinical setting. JAMA Otolaryngol Head Neck Surg 2017;143:1054-5.

33 Henn P, O'Tuathaigh C, Keegan D, et al. Hearing impairment and the amelioration of avoidable medical error: a cross-sectional survey. $J$ Patient Saf 2021;17:e155-60.

34 Cruess SR, Cruess RL, Steinert Y. Supporting the development of a professional identity: general principles. Med Teach 2019;41:641-9.
35 Chang LY, Eliasz KL, Cacciatore DT, et al. The transition from medical student to resident: a qualitative study of new residents' perspectives. Acad Med 2020;95:1421-7.

36 Lynch D. Personal journey and perspective from psychiatric nurse and medical student to intern doctor during COVID-19. Ir J Psychol Med 2020;37:178-80.

37 Lave J, Wenger E. Legitimate peripheral participation in communities of practice. situated learning: legitimate peripheral participation. Cambridge: Cambridge University Press, 1991.

38 Chandran L, luli RJ, Strano-Paul L, et al. Developing "a Way of Being": Deliberate approaches to professional identity formation in medical education. Acad Psychiatry 2019;43:521-7.

39 Cohen JS, Patten S. Well-Being in residency training: a survey examining resident physician satisfaction both within and outside of residency training and mental health in Alberta. BMC Med Educ 2005;5:21.

40 Thompson N, Corbett S, Larsen L, et al. Contemporary experience of stress in UK Foundation level doctors. Clin Teach 2009;6:83-6.

41 Shanafelt TD, Bradley KA, Wipf JE, et al. Burnout and self-reported patient care in an internal medicine residency program. Annals Intern Med 2002;36:358-67.

42 Dyrbye LN, Burke SE, Hardeman RR, et al. Association of clinical specialty with symptoms of burnout and career choice regret among US resident physicians. JAMA 2018;320:1114-30.

43 Rodrigues $\mathrm{H}$, Cobucci R, Oliveira A, et al. Burnout syndrome among medical residents: a systematic review and meta-analysis. PLoS One 2018:13:10.1371/journal.pone.0206840.

44 Buddeberg-Fischer B, Klaghofer R, Stamm M, et al. Work stress and reduced health in young physicians: prospective evidence from Swiss residents. Int Arch Occup Environ Health 2008;82:31-8.

45 Mata DA, Ramos MA, Bansal N, et al. Prevalence of depression and depressive symptoms among resident physicians: a systematic review and meta-analysis. JAMA 2015;314:2373-83.

46 Lue B-H, Chen H-J, Wang C-W, et al. Stress, personal characteristics and burnout among first postgraduate year residents: a nationwide study in Taiwan. Med Teach 2010;32:400-7.

47 Satterfield JM, Becerra C. Developmental challenges, stressors and coping strategies in medical residents: a qualitative analysis of support groups. Med Educ 2010;44:908-16.

48 Tallentire VR, Smith SE, Skinner J, et al. Understanding the behaviour of newly qualified doctors in acute care contexts. Med Educ 2011;45:995-1005

49 Van Hamel C, Jenner LE. Prepared for practice? A national survey of UK Foundation doctors and their supervisors. Med Teach 2015;37:181-8

50 Nestor S, O' Tuathaigh C, O' Brien T. Assessing the impact of COVID-19 on healthcare staff at a combined elderly care and specialist palliative care facility: a cross-sectional study. Palliat Med 2021;23:2692163211028065.

51 Verdonk P, Räntzsch V, de Vries R, et al. Show what you know and deal with stress yourself: a qualitative interview study of medical interns' perceptions of stress and gender. BMC Med Educ 2014:14:10.1186/1472-6920-14-96.

52 Monrouxe LV, Grundy L, Mann M, et al. How prepared are UK medical graduates for practice? a rapid review of the literature 20092014. BMJ Open 2017;7:e013656.

53 Knobloch AC, Ledford CJW, Wilkes S, et al. The impact of near-peer teaching on medical students' transition to clerkships. Fam Med 2018;50:58-62.

54 Donohoe J, O'Rourke M, Hammond S, et al. Strategies for enhancing resilience in medical students: a group concept mapping analysis. Acad Psychiatry 2020;44:427-31.

55 Mavor KI, McNeill KG, Anderson K, et al. Beyond prevalence to process: the role of self and identity in medical student well-being. Med Educ 2014;48:351-60.

56 Busireddy KR, Miller JA, Ellison K, et al. Efficacy of interventions to reduce resident physician burnout: a systematic review. J Grad Med Educ 2017:9:294-301.

57 Covid-19 in Ireland, 2020. Available: https://data.oireachtas.ie/ie/ oireachtas/libraryResearch/2020/2020-05-22_I-rs-infographic-covid19-in-ireland-at-reopening-phase-1-a-statistical-snapshot_en.pdf [Accessed 05 Oct 2020].

58 de Souza WM, Buss LF, Candido DDS. Epidemiological and clinical characteristics of the COVID-19 epidemic in Brazil. Nature Hum Behav 2020;4:856-65.

59 Farooq AR, lqbal S, Abdulaziz N, et al. Professional and personal opinions of doctors in training during the first wave of the COVID19 pandemic. Ir J Med Sci 2021;5:1-7. 